never searched for nests, to believe that one could be found in every bush in which it was sought. It is to be regretted that the author did not put his evidently considerable knowledge of nesting-habits into different form. The succeeding chapter, on curious nestingplaces, where the author's experience is told straightforwardly, is much better. The concluding chapters, on photographing animals and flowers and on protective colouration, are so sketchy as to be of little practical use, and we note some mistakes, e.g. the statement on p. I6 I about the cause of colour differences in moths probably has no foundation.

The style of the whole book is colloquial, and sometimes marred by not very successful attempts at wit.

The book is illustrated by a number of very pretty photographs, which are distinctly good, but not of the striking character made familiar by some other nature-photography works. Nearly all are stereoscopic, and a stereoscope is supplied with the book which adds considerably to their usefulness. Unfortunately, the stereoscope makes the texture of the process-block unpleasantly conspicuous. Although the photographs are not especially striking, they illustrate well the kind of work which an amateur who is limited in time or means may hope to produce.

\section{THE NEW COMET (igroa).}

THE comet discovered near Johannesburg on Nature, has justified the opinion then expressed as to its becoming a brilliant object in our evening skies. From many parts of the civilised world we hear of crowds gathering to watch the rare phenomenon, and the daily Press, despite the General Election excitement, has devoted considerable space to the description of the "Daylight Comet."

Apparently the comet was first seen by some miners on January 16 , and reported to Mr. Innes, of the Transvaal Observatory, Johannesburg. Messrs. Worssell and Innes made the first measurement of its position at Igh. $29^{\circ} 2 \mathrm{~m}$. G.M.T. January I6, that is, at $9.29 \mathrm{a} . \mathrm{m}$. on January I7 local standard time, when the sun would be well above the horizon. The measures were continued until January I7, oh. $8.6 \mathrm{~m}$. (Johannesburg M.T.), that is, midday, and they showed that the comet was rapidly approaching the sun, the apparent movement per hour being $+42 \mathrm{~S}$. in R.A. and $+65^{\prime}$ in declination.

$\mathrm{Mr}$. Innes described the comet as having a head $5^{\prime}$ in diameter, and a well-developed tail; in a later message the latter was stated to be $\mathrm{x}^{\circ}$ long, fanshaped, and visible to the naked eye. This observation emphasises the exceptional brilliance of the comet and the purity of the Transvaal atmosphere, for at the time of observation the comet was within $4 \frac{1}{2}^{\circ}$ of the sun and west of it.

The apparent motion was so rapid that by the time the discovery was announced here the comet had passed to the east of the sun, and was therefore to be seen at or after sunset instead of before or at sunrise. The Cambridge Observatory appears to have been the most fortunately situated of English observatories, for the sky was clear enough on January I9 to warrant an attack in force, and Mr. Hubrecht was, according to Saturday's Daily Mail, fortunate enough to find the comet straight away. Mr. Hinks thereupon secured a measure of the position, and saw a nucleus as bright as Mercury, and a tail $2^{\circ}$ long; on Thursday, January 20 , the nucleus was seen to be brighter and the tail further developed.

According to a Central News correspondent, the comet was seen, in full daylight, at the Milan Observatory, but no tail was seen. The observations of the tail vary considerably in their estimates of its length, but this is to be expected, for, obviously, the prominence of such a filmy structure in daylight or twilight will vary greatly with the purity of the atmosphere.

At Oxford, Prof. Turner found the comet quite a conspicuous object, in field-glasses, at $5 \mathrm{p} . \mathrm{m}$. on January 20 , and could see it quite easily with the naked eye; he made his observations from the Robinson Tower of New College.

On Friday, January $2 \mathrm{I}$, the Cambridge observers were again favoured, and, according to the Times, Mr. Hinks found the comet to be considerably brighter than on the preceding day, and to have a fine stellar nucleus with the surrounding envelopes well developed. Prof. Dyson, at the Royal Observatory, Edinburgh, also saw the nucleus. The same day, Mr. J. H. Elgie, observing at Leeds, saw the comet at 5 p.m., and describes it as "weirdly magnificent," having a tail $8^{\circ}$ long. The nucleus, he estimated, was as bright as Mars at the recent opposition, and the tail was curved, with the concave side towards Venus; the outer edge was then well defined, but further observations, on Saturday, showed it to be much more diffused. The Rev. F. J. Jervis-Smith, writing from Lymington, says that several persons observing there on January 22 thought the tail appeared to flash slightly and continuously, but this phenomenon may have been due to the low position of the object and consequent atmospheric effects.

The lengthy reports in Monday's Times, Daily Mail, Chronicle, \&c., show that the comet was well observed during the week-end. On Saturday, January 22, Prof. Turner secured two photographs showing the brighter portions of the tail, and four photographs were taken at the Dunsink Observatory. Dr. Whittaker and his assistants at Dunsink also observed the comet visually, and found that, in addition to the tail, extending upwards to a distance of $8^{\circ}$, where it was lost in a dense cloud, there was a distinct jet, or horn, of light on that side of the head nearest to the horizon. The head of the comet appeared as a dusky-red nucleus surrounded by a nebulous envelope of fainter red, and was as large as, or larger than, Mars. The twin tails were of a bright yellow colour.

Dr. Rambaut observed the comet with the ro-inch and 18-inch telescopes at the Radcliffe Observatory on January 22, and saw it quite well, despite a thick haze. Prof. Dyson also made observations at Edinburgh, and found, at 5.25 p.m., that the head was as bright as Mars and had a nucleus $45^{\prime \prime}$ in diameter, whilst the tail extended to a distance of $7^{\circ}$. At Cambridge it was estimated to be $6^{\circ}$ long. The orbit computed by Messrs. Stratton and Hubrecht, at Cambridge, shows that the comet passed through perihelion on January $\mathrm{I} 7$, at a distance of two million miles from the sun, and will continue to move northwards with diminishing speed.

At the Solar Physics Observatory, South Kensington, and, we understand, at the Royal Observatory, Greenwich, the careful preparations for observing, and the constant attendance of the staff during the hours available for observations, were, until Tuesday evening, rendered nugatory by clouds, or by the persistent smoky haze which, even on Saturday, rendered Venus a faint object, and made quite hopeless the careful search for the comet. But on Tuesday evening observations were secured by Dr. W. J. S. Lockyer, using the ro-inch refractor, and these showed that, at 5.35 p.m., the Kiel position was in error to a slight extent in R.A. and about $2^{\circ}$ in declination, the observed place being further south than that indicated by the ephemeris.

In a telegram transmitted by Prof. Pickering to the

NO. 2 100, VOL. 82] 
Astronomische Nachrichten (supp. No. 4383) it is announced that Dr. Wright, of the Lick Observatory, has made a daylight observation which shows the spectrum of the comet's nucleus to be continuous, with the sodium, D, lines bright. Similar observations are reported in the Daily Tele graph (January 24) from the Glasgow Observatory, with the addition of a "hydrocarbon" band. This occurrence of the D lines recalls the Wells's, and the Great, comets of 1882 , in which Copeland and Lohse observed the same lines intensely bright, due, according to Copeland, to the near approach of the comet to the sun. In the present case the rapidity with which the comet appears to have travelled when near perihelion further suggests a similarity.

The publication of a set of elements and an ephemeris by the Kiel Centralstelle (Circular No. II 7 ) provides for observations during the next few days. The elements are based on observations made at Algiers on January I8, I9, and 20 , and are as follows :-

$$
\begin{aligned}
& \text { Elements. } \\
& \mathrm{T}=\mathrm{I} 910 \text {, January } 177^{\circ} \text { (M.T. Beılin). } \\
& \left.\omega=263^{\circ}, 57^{\circ}\right) \\
& \left.\delta=8^{\circ} 56 \cdot^{\prime}\right\} 1910.0 \\
& i=62^{\circ} \mathrm{I} 66^{\prime} \mathrm{I}^{\prime} \\
& \log q=8 \cdot 6169
\end{aligned}
$$

\begin{tabular}{|c|c|c|c|c|}
\hline Igro & & h. $\stackrel{\text { m. }}{\mathrm{m} .}$ & & Decl. \\
\hline anuary 26 & ... & $2125^{\circ} 3$ & $\ldots$ & to 2 \\
\hline 27 & ․ & $2 I 3 I * 2$ & $\ldots$ & +23 \\
\hline 28 & $\ldots$ & $21 \quad 36.7$ & $\ldots$ & \\
\hline 29 & ... & 2 I 42 I & $\ldots$ & \\
\hline 30 & $\ldots$ & $2147^{\prime 2}$ & $\ldots$ & +745 \\
\hline
\end{tabular}

The following is an abstract from the ephemeris:-

$$
\text { Ephemeris for oh. (M.T. Berlin). }
$$

Observations made by Prof. Turner, Dr. Lockyer, and others, indicate that this ephemeris is incorrect in declination, and that on January 25 the observed position was about $2^{\circ}$ south of that given by the ephemeris. Prof. Turner reports that the discordance is increasing.

Observations made on January 24 and 25 indicate that the comet's brightness is decreasing. In the Times of January 25, Sir Robert Ball reported that "Prof. Newall finds a remarkable spectrum," and the Rev. T. E. R. Phillips stated that the double tail was not unlike that of the great comet of $\mathrm{x} 874$, but with the gap in the centre much wider than in that case. Further photographs were secured at Dunsink and Oxford on Tuesday. In the Times of January 26 Sir Robert Ball reports that the comet was again observed, between 5 and 6 p.m. on Tuesday. It was much fainter than on Saturday, but the tail was quite $10^{\circ}$ long, and was slightly curved towards Venus. The bright yellow light was still present, but fainter.

Bright, "daylight," comets are not frequent visitors; the tale for the nineteenth century is practically completed by the comets of $1843,1847,1853,1861$, and I882, and it is a curious coincidence that this present visitor should arrive at the time when we had settled down to the carefully ordered study of the rediscovered Halley. But reference to the notes presented to the Royal Astronomical Society by Messrs. Cowell and Crommelin will show that the coincidence is not unique; quite a number of returns of Halley's comet have been marked by the appearance of exceptionally bright sporadic visitors.

The present object has been introduced to us under a misnomer. The Astronomische Nachrichten now tells us that the appellation "Drake" is simply due to a misinterpretation of "great" as the message was being transmitted by telephone; popularly it is the "Daylight Comet."

W. E. Rolston.

\section{NOTES.}

WE regret to see the announcement of the death, at Marburg, of Prof. F. Kohlrausch, the distinguished physicist, at seventy years of age.

THE death is announced, at sixty-two years of age, of Prof. H. Brunner, professor of toxicological chemistry in the University of Lausanne since 1876 .

THE Friday evening discourse at the Royal Institution on February 4 will be delivered by Prof. W. Bateson, F.R.S., on "The Heredity of Sex."

Prof. A. Lacrorx has been elected president for I9Io of the Geological Society of France. M. Ehlert, Mme. Qhilert, Prof. Vidal, and M. Cossmann have been elected vice-presidents. This is the first time a lady has been elected to office in the society.

To the Field of January $22 \mathrm{Mr}$. Lydekker contributes an account of an apparently new race of buffalo obtained by Mr. Hilton-Simpson in the extreme south of French Congoland; the race appears to be allied to the red Congo buffalo, but is of much darker colour.

According to a statement in the Times of January 17 , three skeletons of sauropod dinosaurs have recently been discovered in the Jurassic strata of Utah by a collector from the Carnegie Museum, Pittsburg. One of the three is stated to be higher and more massive than that of the type of Diplodocus carnegiei, although its length -84 feet -is somewhat less.

The council of the Royal Geographical Society has decided to award a special gold medal to Commander Peary for his journey to the North Pole, and for having undertaken such scientific investigations as his opportunities permitted; and a silver replica to Captain Bartlett for attaining eighty-eight degrees north latitude.

According to the New York correspondent of the Times, the U.S. Department of Commerce and Labour has under consideration the dispatch of the Government steamship Albatross on an expedition to the Antarctic Ocean. The expedition is the suggestion of Dr. H. F. Osborn, of the American Museum of Natural History, New York. The objects of the proposed expedition are stated to be partly commercial and partly scientific. There appears to be reason to believe that some of the remote southern islands are the homes of herds of the southern fur seal, and it is hoped to discover these, as well as to study south polar fauna generally.

A SERIEs of lectures in connection with the Selborne Society has been arranged, and will be held in the theatre of the Civil Service Commission, Burlington Gardens, London, W. The first lecture of the course was delivered by Mr. F. Enoch on January 2I, and dealt with insects through the camera. There was a large audience. The lecture, which aroused great enthusiasm, gave the results of many years of patient outdoor research, and was illustrated by a unique series of three-colour photographs. On February in Mr. W. Bickerton will lecture on wild birds and their ways; on March I , Mr. W. M. Webb on clothes a human nature-study; and, on April 1., - Miss Gertrude Bacon on wind, wave, and cloud. Fuller particulars may be obtained from the honorary general secretary of the society, 42 Bloomsbury Square, London, W.C.

IT is with regret that we see the announcement of the unexpected death of Dr. W. Page-May, fellow and lecturer of University College, London, which occurred quite suddenly at Brighton on Wednesday, January ig. To 